\title{
Author Correction: Predictive modelling of structure formation in semiconductor films produced by meniscus-guided coating
}

Jasper J. Michels (D), Ke Zhang, Philipp Wucher, Pierre M. Beaujuge, Wojciech Pisula and Tomasz Marszalek

Correction to: Nature Materials https://doi.org/10.1038/s41563-020-0760-2, published online 10 August 2020.

In the version of this Article originally published, in Fig. 4a the region in the lower-right corner was mistakenly labelled 'Scenarios I and II'; it should have been labelled 'Scenarios III and IV'. This has now been corrected.

In addition, due to a publishing error, some of the equations in the Methods sections of the PDF version appeared in the wrong places. The HTML version, however, was correct. The PDF has now been updated.

Published online: 24 August 2020

https://doi.org/10.1038/s41563-020-00810-6

(c) The Author(s), under exclusive licence to Springer Nature Limited 2020

\section{Publisher Correction: Predictive modelling of structure formation in semiconductor films produced by meniscus-guided coating}

Jasper J. Michels D, Ke Zhang, Philipp Wucher, Pierre M. Beaujuge, Wojciech Pisula and Tomasz Marszalek

Correction to: Nature Materials https://doi.org/10.1038/s41563-020-0760-2, published online 10 August 2020.

In the version of this Article originally published, the first term of equation (2) was missing a minus sign and incorrectly read $\frac{\partial \eta_{i}(\mathbf{r}, t)}{\partial t}$; it should have read $-\frac{\partial \eta_{i}(\mathbf{r}, t)}{\partial t}$. This has now been corrected in all versions of the Article.

\section{Publisher Correction: Predictive modelling of structure formation in semiconductor films produced by meniscus-guided coating}

Jasper J. Michels Di , Ke Zhang, Philipp Wucher, Pierre M. Beaujuge, Wojciech Pisula and Tomasz Marszalek

Correction to: Nature Materials https://doi.org/10.1038/s41563-020-0760-2, published online 10 August 2020.

The previous Publisher Correction for this Article described the addition of a minus sign to the left-hand term of equation (2), when it should have been added to the first term on the right of the equation. The corrected equation is shown below, and all versions of the original Article have been updated accordingly.

$$
\frac{\partial \eta_{i}(\mathbf{r}, t)}{\partial t}=-\Gamma(\phi) \frac{\partial F}{\partial \eta_{i}}+\theta_{\eta_{i}}(\mathbf{r}, t)
$$

Published online: 1 October 2020

https://doi.org/10.1038/s41563-020-00843-X

(c) The Author(s), under exclusive licence to Springer Nature Limited 2020 